\title{
2015/16 seasonal vaccine effectiveness against hospitalisation with influenza A(H1N1)pdm09 and $B$ among elderly people in Europe: results from the I-MOVE+ project
}

M Rondy ${ }^{1}$, A Larrauri ${ }^{23}$, I Casado ${ }^{34}$, V Alfonsi 5 , D Pitigoi 6 , 0 Launay ${ }^{78}$, RK Syrjänen 9 , G Gefenaite ${ }^{10}$, A Machado ${ }^{11}$, VV

Vučina ${ }^{12}$, JK Horváth ${ }^{13}$, I Paradowska-Stankiewicz ${ }^{14}$, SD Marbus ${ }^{15}$, A Gherasim ${ }^{23}$, JA Díaz-González ${ }^{4}$, C Rizzo ${ }^{5}$, AE Ivanciuc ${ }^{16}$, F Galtier ${ }^{17}$, N Ikonen ${ }^{18}$, A Mickiene ${ }^{10}$, V Gomez ${ }^{11}$, S Kurečić Filipović ${ }^{12}$, A Ferenczi ${ }^{13}$, MR Korcinska ${ }^{14}$, R van GageldonkLafeber ${ }^{15}$, I-MOVE+ hospital working group ${ }^{19}, M$ Valenciano ${ }^{1}$

1. EpiConcept, Paris, France

2. National Centre of Epidemiology, Institute of Health Carlos III, Madrid, Spain

3. CIBER Epidemiología y Salud Pública, Institute of Health Carlos III, Madrid, Spain

4. Instituto de Salud Pública de Navarra, IdiSNA, Pamplona, Spain

5. Istituto Superiore di Sanità, Rome, Italy

6. UMF Carol Davila, INC Cantacuzino, Bucharest, Romania

7. Inserm, F-CRIN, Innovative clinical research network in vaccinology (I-REIVAC), Paris, France

8. Université Paris Descartes, Sorbonne Paris Cité, APHP, CIC Cochin-Pasteur, Paris, France

9. Impact Assessment Unit, National Institute for Health and Welfare, Tampere, Finland

10. Department of Infectious diseases, Lithuanian University of Health Sciences, Kaunas, Lithuania

11. Epidemiology Research Unit, Epidemiology Department, National Health Institute Dr Ricardo Jorge, Lisbon, Portugal

12. Epidemiology Service, Croatian Institute of Public Health, Zagreb, Croatia

13. Office of the Chief Medical Officer, Budapest, Hungary

14. National institute of Public Health - National Institute of Hygiene, Department of Epidemiology, Warsaw, Poland

15. Centre for Epidemiology and surveillance of infectious diseases, Centre for infectious disease control, National Institute for

Public Health and the Environment (RIVM), Bilthoven, The Netherlands

16. INC Cantacuzino, Bucharest, Romania

17. CIC de Montpellier, Hôpital Saint-Eloi, CHU de Montpellier, Montpellier, France

18. Viral Infections Unit, National Institute for Health and Welfare, Helsinki, Finland

19. The I-MOVE+ hospital working group is listed at the end of the article

Correspondence: Marc Rondy (m.rondy@epiconcept.fr)

Citation style for this article:

Rondy M, Larrauri A, Casado I, Alfonsi V, Pitigoi D, Launay O, Syrjänen RK, Gefenaite G, Machado A, Vučina VV, Horváth JK, Paradowska-Stankiewicz I, Marbus SD, Gherasim A, Díaz-González JA, Rizzo C, Ivanciuc AE, Galtier F, Ikonen N, Mickiene A, Gomez V, Kurečić Filipović S, Ferenczi A, Korcinska MR, van Gageldonk-Lafeber R, I-MOVE+ hospital working group, Valenciano M. 2015/16 seasonal vaccine effectiveness against hospitalisation with influenza A(H1N1)pdmo9 and B among elderly people in Europe: results from the I-MOVE+ project. Euro Surveill. 2017;22(30):pii=30580. DOI: http://dx.doi.org/10.2807/1560-7917.ES.2017.22.30.30580

Article submitted on 13 October 2016 / accepted on 08 February 2017 / published on 30 July 2017

We conducted a multicentre test-negative case-control study in 27 hospitals of 11 European countries to measure 2015/16 influenza vaccine effectiveness (IVE) against hospitalised influenza $A\left(\mathrm{H}_{1} \mathrm{~N}_{1}\right)$ pdmog and $B$ among people aged $\geq 65$ years. Patients swabbed within 7 days after onset of symptoms compatible with severe acute respiratory infection were included. Information on demographics, vaccination and underlying conditions was collected. Using logistic regression, we measured IVE adjusted for potential confounders. We included 355 influenza $A\left(\mathrm{H}_{1} \mathrm{~N}_{1}\right)$ pdmog cases, 110 influenza $B$ cases, and 1,274 controls. Adjusted IVE against influenza $A\left(\mathrm{H}_{1} \mathrm{~N}_{1}\right)$ pdmog was $42 \%$ ( $95 \%$ confidence interval (Cl): 22 to 57 ). It was $59 \%$ (95\% Cl: 23 to 78 ), $48 \%$ (95\% Cl: 5 to 71 ), $43 \%$ (95\% Cl: 8 to 65 ) and $39 \%$ ( $95 \% \mathrm{Cl}: 7$ to 60 ) in patients with diabetes mellitus, cancer, lung and heart disease, respectively. Adjusted IVE against influenza B was $52 \%$ (95\% Cl: 24 to 70$)$. It was $62 \%$ ( $95 \% \mathrm{Cl}: 5$ to 85$), 60 \%$ (95\% Cl: 18 to 80 ) and $36 \%(95 \% \mathrm{Cl}:-23$ to 67$)$ in patients with diabetes mellitus, lung and heart disease, respectively. 2015/16 IVE estimates against hospitalised influenza in elderly people was moderate against influenza $A\left(\mathrm{H}_{1} \mathrm{~N}_{1}\right)$ pdmo9 and $B$, including among those with diabetes mellitus, cancer, lung or heart diseases.

\section{Background}

Elderly populations, defined as those aged 65 years and above, and, more specifically, elderly people with underlying conditions, are at increased risk for hospitalisation due to influenza [1]. Influenza may also increase the severity of underlying chronic lung diseases, probably through inflammatory processes [2]. Viral pneumonia due to influenza seems to predispose to myocardial infarction, and congestive heart failures are more common during influenza seasons [3]. Patients with cancer treated with chemotherapy [4] and diabetic patients are more vulnerable to influenza. Their impaired immune response [5] could also affect host response to vaccination $[6,7]$. Evidence of 


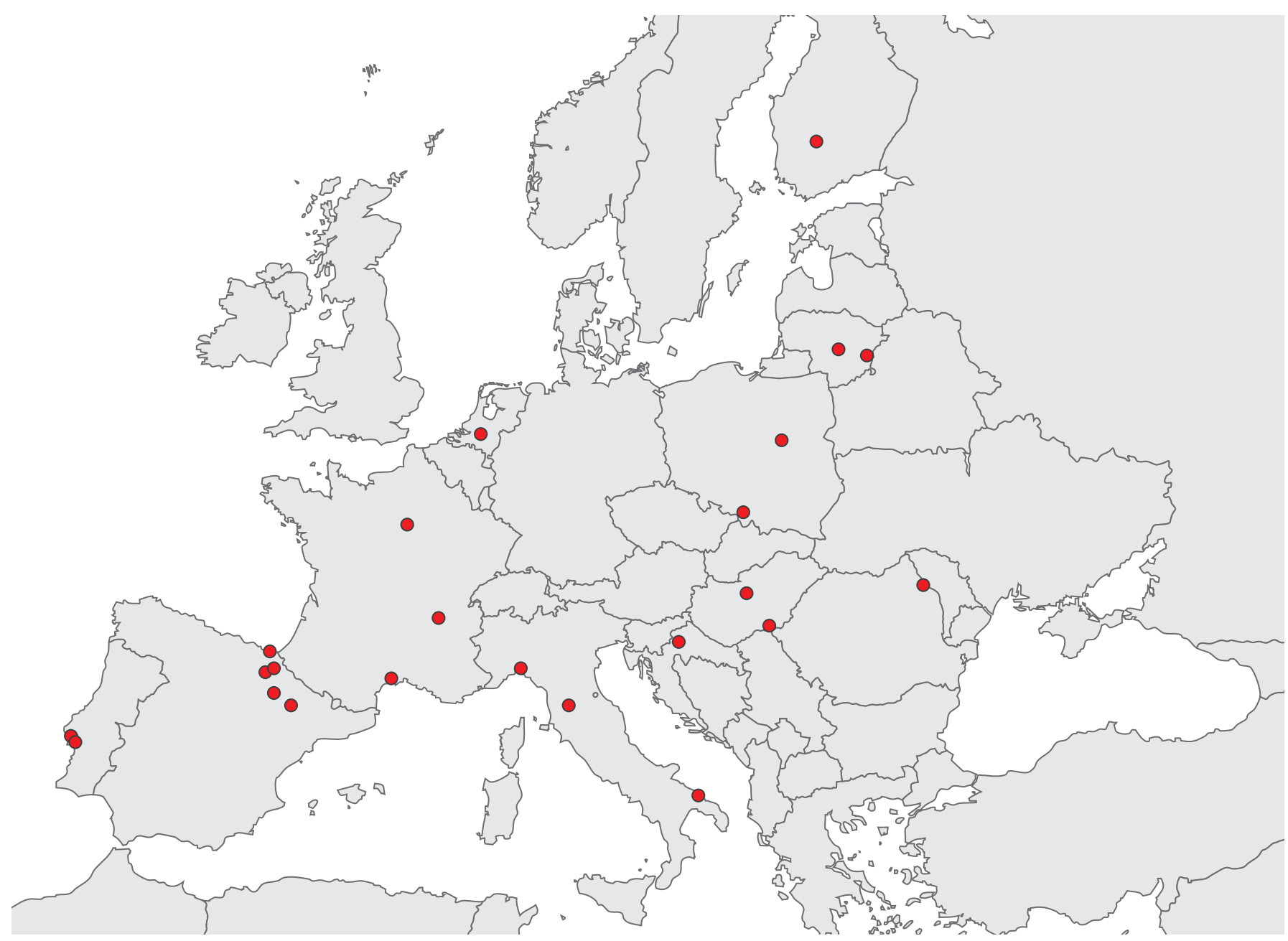

I MOVE+: Integrated Monitoring of Vaccines in Europe plus.

Each dot represents one location and there may be more than one hospital in one location.

the effectiveness of influenza vaccination in preventing severe clinical outcomes was recently described as low or very low among elderly people [8], and among patients with cancer [9], diabetes mellitus [10], lung diseases [11] [12], or cardiovascular diseases [13].

Despite the Council of the European Union and the World Health Organization's (WHO) recommendations to annually vaccinate elderly people $[14,15]$, influenza vaccine coverage among elderly people remains below the $75 \%$ target in most European countries [16].

In this context, post-marketing studies to estimate the influenza vaccine effectiveness (IVE) among elderly people are needed to inform about vaccination benefits for vaccinees, detect subgroups in which the vaccine performs less well and identify vaccine types that perform best. In 2015, to address this issue, the Integrated Monitoring of Vaccines in Europe plus (IMOVE+) consortium initiated a network of hospitals across Europe to measure IVE against laboratory-confirmed hospitalised influenza among elderly people.

The WHO recommended to include in the 2015/16 trivalent influenza vaccine for the northern hemisphere an $\mathrm{A} /$ California/7/2009 ( $\left.\mathrm{H}_{1} \mathrm{~N}_{1}\right)$ pdmog-like virus, an $\mathrm{A} /$ Switzerland/9715293/2013 ( $\mathrm{H}_{3} \mathrm{~N}_{2}$ )-like virus and a B/ Phuket/3073/2013-like virus (Yamagata lineage) [17].

In the 2015/16 influenza season in Europe, influenza $\mathrm{A}\left(\mathrm{H}_{1} \mathrm{~N}_{1}\right)$ pdmog and influenza $B$ (mainly Victoria lineage) viruses predominated [18]. We conducted a multicentre hospital-based test-negative design (TND) case-control study to measure the $2015 / 16$ seasonal IVE against hospitalisation with influenza $A\left(\mathrm{H}_{1} \mathrm{~N}_{1}\right)$ pdmog and influenza $B$ among elderly people in Europe, by risk groups and for specific vaccine types. 


\section{FIGURE 2}

Cases of severe acute respiratory infection with influenza $\mathrm{A}(\mathrm{H} 3 \mathrm{~N} 2), \mathrm{A}(\mathrm{H} 1 \mathrm{~N} 1) \mathrm{pdm} 09$, and $\mathrm{B}$, and negative controls, I-MOVE+ study, Europe, influenza season 2015/16 ( $\mathrm{n}=504$ casesa; $\mathrm{n}=1,274$ controls)

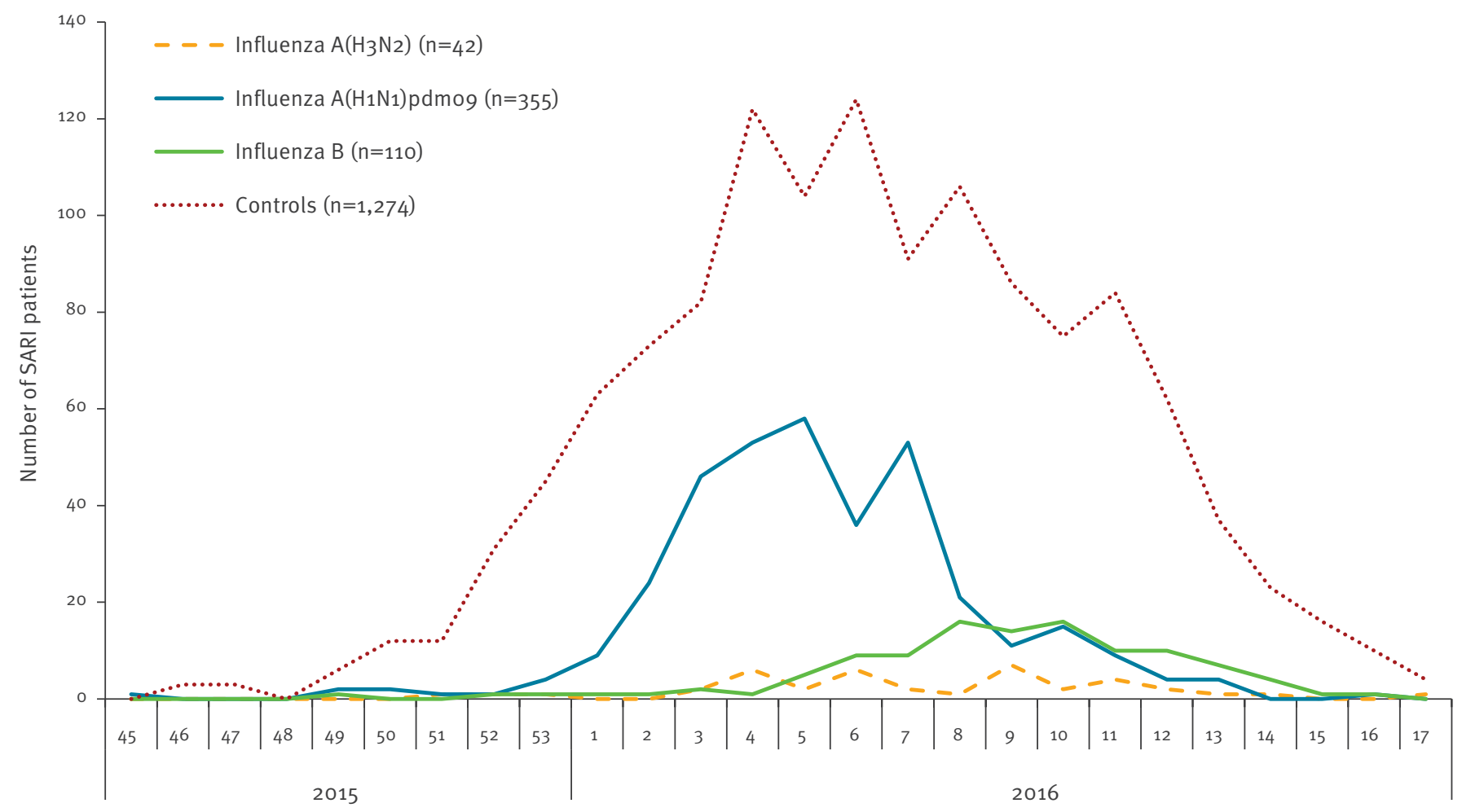

ISO week of symptom onset

I-MOVE+: Integrated Monitoring of Vaccines in Europe plus; ISO: International Organisation for Standardisation; SARI: severe acute respiratory infection.

a Including two influenza $\mathrm{A}\left(\mathrm{H}_{1} \mathrm{~N}_{1}\right)$ pdmog and $\mathrm{B}$ co-infections and one influenza $\mathrm{A}\left(\mathrm{H}_{3} \mathrm{~N}_{2}\right)$ and $\mathrm{B}$ co-infection.

\section{Methods}

\section{Study sites and design}

We set up a European network of 27 hospitals in 11 countries (Croatia, Finland, France, Hungary, Italy, Lithuania, the Netherlands, Poland, Portugal, Romania and Spain) (Figure 1), organised in 12 study sites (in Spain, Navarre region hospitals had their own coordination centre). Each study site adapted a generic protocol to their local setting $[19,20]$. Monitoring visits were organised to ensure the study was done similarly across hospitals. We conducted a multicentre TND case-control study.

\section{Study period}

In each study site, the study period started at least two weeks after the beginning of the vaccination campaign in the respective countries and lasted from the week of the first detection of a laboratory-confirmed case of influenza to the week of the last laboratory-confirmed case of influenza. We defined different study periods for influenza $A\left(\mathrm{H}_{1} \mathrm{~N}_{1}\right)$ pdmog and $B$.

\section{Study population}

Our study population included all community dwelling patients aged 65 years and above who had no contraindication for influenza vaccination or previous laboratory-confirmed influenza in the season and agreed to participate. In the participating services of each hospital, patients admitted for clinical conditions that could be related to influenza were screened for eligibility. Study physicians, nurses or collaborating medical staff asked patients about onset of symptoms compatible with the definition of a severe acute respiratory infection (SARI) in the previous 7 days.

We defined a SARI case as a hospitalised patient with at least one systemic (fever or feverishness, malaise, headache, myalgia or deterioration of general or functional condition) and at least one respiratory sign or symptom (cough, sore throat or shortness of breath) at admission, or within 48 hours after admission.

\section{Data collection}

The hospital study teams swabbed patients meeting the SARI case definition. Specimens were tested by 
Vaccine types used and source of information for vaccination status by study site, I-MOVE + study, Europe, influenza season, 2015/16

\begin{tabular}{|c|c|c|c|c|}
\hline \multirow[b]{2}{*}{ Study site } & \multirow{2}{*}{$\begin{array}{l}\text { Number of } \\
\text { hospitals }\end{array}$} & \multirow[b]{2}{*}{ Vaccines used } & \multicolumn{2}{|c|}{ Data sources } \\
\hline & & & $\begin{array}{l}\text { Source of information } \\
\text { for vaccination status }\end{array}$ & $\begin{array}{l}\text { Source of information } \\
\text { for underlying conditions }\end{array}$ \\
\hline Croatia & 1 & Inactivated subunit & 1 & I; H \\
\hline Finland & 2 & Inactivated split & R; I; GP & I; GP; H \\
\hline France & 3 & $\begin{array}{l}\text { Inactivated subunit; inactivated } \\
\text { split }\end{array}$ & I; P & I; H \\
\hline Hungary & 2 & Adjuvanted & I; GP & I; H \\
\hline Italy & 3 & $\begin{array}{l}\text { Inactivated subunit; inactivated } \\
\text { split; adjuvanted }\end{array}$ & I; GP & I; H \\
\hline Lithuania & 2 & Inactivated subunit & I; GP & $\mathrm{I} ; \mathrm{H}$ \\
\hline Navarre & 3 & Inactivated split & $\mathrm{R}$ & I; GP; H \\
\hline The Netherlands & 1 & $\begin{array}{l}\text { Inactivated subunit; inactivated } \\
\text { split }\end{array}$ & I & I; H \\
\hline Poland & 3 & Unknown & I; GP & $\mathrm{I} ; \mathrm{H}$ \\
\hline Portugal & 2 & $\begin{array}{l}\text { Inactivated subunit; inactivated } \\
\text { split }\end{array}$ & R; I; GP & I; H \\
\hline Romania & 3 & Inactivated subunit & I; GP & $\mathrm{I} ; \mathrm{H}$ \\
\hline Spain & 2 & $\begin{array}{l}\text { Inactivated subunit; inactivated } \\
\text { split }\end{array}$ & R; I; GP & I; H \\
\hline
\end{tabular}

GP: general practitioner/primary care database; H: hospital database/medical charts; I: interview with patient; I-MOVE+: Integrated Monitoring of Vaccines in Europe plus; P: pharmacist; R: register

RT-PCR and patients classified as influenza $A\left(\mathrm{H}_{1} \mathrm{~N}_{1}\right)$ pdmog cases, influenza B cases, other influenza cases or controls if their specimens tested negative for any influenza virus.

The hospital study teams collected information on patients' age and sex, influenza vaccination status including date and brand of the 2015/16 vaccine and the status in two previous seasons and underlying conditions listed for clinical risk groups recommended for influenza vaccination [21]. The underlying conditions included diabetes mellitus, obesity (defined as body mass index $\geq 30 \mathrm{~kg} / \mathrm{m} 2$ ), cardiovascular conditions (such as congenital heart disease, congestive heart failure and coronary artery disease), lung diseases (such as chronic obstructive pulmonary disease, cystic fibrosis, asthma), renal and rheumatologic diseases, cancer, stroke, dementia and cirrhosis. Information on number of hospitalisations for underlying conditions in the previous 12 months, number of general practitioners (GP) visits in the previous three months, smoking status and functional impairment (based on Barthel index score [22]) was also collected.

Information on demographics and underlying conditions were collected from interviews with patients (or their relatives) and hospital and/or primary care databases. In study sites with no vaccination register, vaccination status was collected through interview with patients. For patients vaccinated or unable to provide their vaccination status, study sites called patients' GP or pharmacists to retrieve vaccination status, date and brand (Table 1).

We defined patients as vaccinated with the 2015/16 influenza vaccine if they had been vaccinated at least 14 days before symptoms onset. Otherwise, they were considered as unvaccinated.

\section{Data analysis}

We computed the IVE as ( 1 minus the odds ratio (OR) of vaccination between cases and controls) $\times 100$. We performed a pooled one-stage analysis using the study site as a fixed effect and estimated IVE stratified on the presence of underlying conditions. All IVE estimates were adjusted for study site, date of SARI symptom onset and age modelled as restricted cubic splines with four knots (initial model). To adjust for additional potential confounders (sex, each group of underlying conditions, hospitalisation in the past year, more than one GP visit in the past 3 months, functional impairment, current smoking), we performed a multivariable analysis using an onward step by step modelling and analysing them as dichotomous variables. Patients with missing covariates were excluded from the analyses adjusted for these covariates. We retained in the model (full model) all covariates that changed the IVE estimate by $10 \%$ of more (relative change).

We grouped the vaccine brands in split virion, subunit or adjuvanted vaccines. To compute vaccine typespecific effectiveness, we restricted our analyses to 
TABLE 2

Characteristics of influenza A(H1N1)pdm09 and influenza B hospitalised cases and corresponding test-negative controls included in the I-MOVE + study, Europe, influenza season 2015/16

\begin{tabular}{|c|c|c|c|c|c|c|c|c|}
\hline & \multicolumn{4}{|c|}{ Influenza A(H1N1)pdmog } & \multicolumn{4}{|c|}{ Influenza B } \\
\hline & \multicolumn{2}{|c|}{$\begin{array}{l}\text { Cases } \\
(n=355)\end{array}$} & \multicolumn{2}{|c|}{$\begin{array}{l}\text { Controls } \\
(n=976)\end{array}$} & \multicolumn{2}{|c|}{$\begin{array}{c}\text { Cases } \\
(n=110)\end{array}$} & \multicolumn{2}{|c|}{$\begin{array}{c}\text { Controls } \\
(n=1,015)\end{array}$} \\
\hline & $\mathrm{n}$ & $\%$ & $\mathrm{n}$ & $\%$ & $\mathrm{n}$ & $\%$ & $\mathrm{n}$ & $\%$ \\
\hline Median age in years (range) & $76(65-95)$ & - & $78(65-101)$ & - & $76(65-94)$ & - & $78(65-101)$ & - \\
\hline Aged $65-79$ years & $235 / 355$ & 66.2 & $535 / 976$ & $54.8^{\mathrm{a}}$ & $76 / 110$ & 69.1 & $566 / 1,015$ & $55.8^{\mathrm{a}}$ \\
\hline Sex $=$ male & $194 / 351$ & $55 \cdot 3$ & $512 / 975$ & 52.5 & $57 / 110$ & 51.8 & $520 / 1,014$ & 51.3 \\
\hline $\begin{array}{l}2015 / 16 \text { seasonal influenza } \\
\text { vaccination }\end{array}$ & $138 / 355$ & 38.9 & $543 / 976$ & $55.6^{\mathrm{a}}$ & $50 / 110$ & $45 \cdot 5$ & $588 / 1,015$ & $57.9^{\mathrm{a}}$ \\
\hline $\begin{array}{l}2014 / 15 \text { seasonal influenza } \\
\text { vaccination }\end{array}$ & $136 / 347$ & 39.2 & $537 / 958$ & $56.1^{\mathrm{a}}$ & $53 / 109$ & 48.6 & $589 / 998$ & $59.0^{a}$ \\
\hline \multicolumn{9}{|l|}{ Type of vaccine } \\
\hline Not vaccinated & $217 / 353$ & 61.5 & $433 / 970$ & $44.6^{\mathrm{a}}$ & $60 / 110$ & 54.5 & $427 / 1012$ & $42.2^{\mathrm{a}}$ \\
\hline Inactivated subunit & $77 / 353$ & 21.8 & $209 / 970$ & 21.5 & $20 / 110$ & 18.2 & $207 / 1012$ & 20.5 \\
\hline Inactivated split virion & $59 / 353$ & 16.7 & $312 / 970$ & 32.2 & $30 / 110$ & $27 \cdot 3$ & $332 / 1012$ & 32.8 \\
\hline Adjuvanted & $0 / 353$ & 0.0 & $16 / 970$ & 1.6 & $0 / 110$ & 0.0 & $46 / 1012$ & 4.5 \\
\hline \multicolumn{9}{|l|}{ Underlying conditions } \\
\hline Diabetes & $99 / 347$ & 28.5 & $277 / 954$ & 29.0 & $31 / 104$ & 29.8 & $284 / 992$ & 28.6 \\
\hline Heart disease & $215 / 351$ & 61.3 & $590 / 967$ & 61.0 & $63 / 107$ & 58.9 & $631 / 1,006$ & 62.7 \\
\hline Lung disease & $141 / 351$ & 40.2 & $438 / 965$ & 45.4 & $46 / 108$ & 42.6 & 484/996 & 48.6 \\
\hline Immunodeficiency & $7 / 343$ & 2.0 & $34 / 942$ & 3.6 & $10 / 106$ & 9.4 & $32 / 986$ & $3.2^{\mathrm{a}}$ \\
\hline Cancer & $93 / 350$ & 26.6 & $263 / 963$ & 27.3 & $19 / 105$ & 18.1 & $280 / 1,001$ & $28.0^{\mathrm{a}}$ \\
\hline Nutritional deficiency & $16 / 239$ & 6.7 & $65 / 723$ & 9.0 & $9 / 84$ & 10.7 & $51 / 753$ & 6.8 \\
\hline Renal disease & $54 / 349$ & 15.5 & $221 / 960$ & $23.0^{\mathrm{a}}$ & $20 / 106$ & 18.9 & $236 / 996$ & 23.7 \\
\hline Dementia or stroke & $46 / 346$ & $13 \cdot 3$ & $160 / 956$ & 16.7 & $17 / 104$ & 16.3 & $156 / 991$ & 15.7 \\
\hline Rheumatologic disease & $15 / 246$ & 6.1 & $80 / 737$ & $10.9^{\mathrm{a}}$ & $11 / 87$ & 12.6 & $83 / 757$ & 11.0 \\
\hline Obesity $^{\mathrm{b}}$ & $43 / 349$ & 12.3 & $139 / 951$ & 14.6 & $5 / 104$ & 4.8 & $123 / 985$ & $12.5^{\mathrm{a}}$ \\
\hline Any underlying condition & $325 / 350$ & 92.9 & $908 / 976$ & 93.0 & $99 / 110$ & 90.0 & $955 / 1,015$ & 94.1 \\
\hline$\geq 2$ underlying conditions & $244 / 347$ & 70.3 & $719 / 964$ & 74.6 & $72 / 108$ & 66.7 & $752 / 1,006$ & 74.8 \\
\hline Functional impairment ${ }^{c}$ & $116 / 347$ & 33.4 & $347 / 948$ & 36.6 & $20 / 109$ & 18.3 & $359 / 988$ & $36.3^{\mathrm{a}}$ \\
\hline Hospitalisation in past 12 months & $152 / 345$ & 44.1 & $446 / 960$ & 46.5 & $39 / 108$ & 36.1 & $475 / 989$ & $48.0^{\mathrm{a}}$ \\
\hline Current smoking & $79 / 340$ & 23.2 & $183 / 901$ & 20.3 & $36 / 102$ & $35 \cdot 3$ & $210 / 927$ & $22.7^{\mathrm{a}}$ \\
\hline \multicolumn{9}{|l|}{ Study sites } \\
\hline Croatia & $16 / 355$ & 4.5 & $15 / 976$ & 1.5 & $5 / 110$ & 4.5 & $3 / 1,015$ & 0.3 \\
\hline Finland & $18 / 355$ & 5.1 & $57 / 976$ & 5.8 & $3 / 110$ & 2.7 & $35 / 1,015$ & 3.4 \\
\hline France & $11 / 355$ & 3.1 & $124 / 976$ & 12.7 & $26 / 110$ & 23.6 & $124 / 1,015$ & 12.2 \\
\hline Hungary & $0 / 355$ & 0.0 & $0 / 976$ & 0.0 & $1 / 110$ & 0.9 & $5 / 1,015$ & 0.5 \\
\hline Italy & $3 / 355$ & 0.8 & $102 / 976$ & 10.5 & $10 / 110$ & 9.1 & $249 / 1,015$ & 24.5 \\
\hline Lithuania & $17 / 355$ & 4.8 & $41 / 976$ & 4.2 & $3 / 110$ & 2.7 & $31 / 1,015$ & 3.1 \\
\hline Navarra & $87 / 355$ & 24.5 & $240 / 976$ & 24.6 & $27 / 110$ & 24.5 & $230 / 1,015$ & 22.7 \\
\hline The Netherlands & $5 / 355$ & 1.4 & $12 / 976$ & 1.2 & $3 / 110$ & 2.7 & $6 / 1,015$ & 0.6 \\
\hline Poland & $17 / 355$ & 4.8) & $14 / 976$ & 1.4 & $6 / 110$ & 5.5 & $9 / 1,015$ & 0.9 \\
\hline Portugal & $14 / 355$ & 3.9 & $35 / 976$ & 3.6 & $1 / 110$ & 0.9 & $1 / 1,015$ & 0.1 \\
\hline Romania & $58 / 355$ & 16.3 & $101 / 976$ & 10.3 & $2 / 110$ & 1.8 & $70 / 1,015$ & 6.9 \\
\hline Spain & $109 / 355$ & 30.7 & $235 / 976$ & 24.1 & $23 / 110$ & 20.9 & $252 / 1,015$ & 24.8 \\
\hline \multicolumn{9}{|l|}{ Potential for misclassification } \\
\hline Antivirals before swabbing & $36 / 353$ & 10.2 & $32 / 972$ & $3 \cdot 3^{a}$ & $7 / 107$ & 7.5 & $27 / 1,012$ & $2.7^{\mathrm{a}}$ \\
\hline Swabbing within 3 days of onset & $216 / 355$ & 60.8 & $518 / 976$ & $53.1^{\mathrm{a}}$ & $54 / 110$ & 49.1 & $585 / 1,015$ & 57.6 \\
\hline
\end{tabular}

I MOVE+: Integrated Monitoring of Vaccines in Europe plus.

a Indicates a significant difference ( $p$ value $<0.05$ ) between cases and controls.

${ }^{b}$ Defined as body-mass index $\geq 30 \mathrm{~kg} / \mathrm{m} 2$.

'Defined as Barthel score<100 [22]. 
TABLE 3

Pooled adjusted seasonal influenza vaccine effectiveness against hospitalised influenza A(H1N1)pdm09 overall among elderly people, by risk groups and vaccine type, I-MOVE + study, Europe, influenza season, 2015/16

\begin{tabular}{|c|c|c|c|c|c|}
\hline Analyses & $\begin{array}{l}\text { Model used for } \\
\text { adjustment }^{\mathrm{a}}\end{array}$ & $\begin{array}{l}\text { Vaccinated } \\
\text { /cases }\end{array}$ & $\begin{array}{l}\text { Vaccinated } \\
\text { /controls }\end{array}$ & Adjusted IVE & $95 \% \mathrm{Cl}$ \\
\hline \multicolumn{6}{|l|}{ Overall } \\
\hline & Initial & $138 / 355$ & $543 / 976$ & 42.4 & 22.0 to 57.4 \\
\hline & Full & $131 / 336$ & $509 / 923$ & 39.4 & 16.6 to 55.9 \\
\hline \multicolumn{6}{|l|}{ By risk groups } \\
\hline \multirow{2}{*}{ At least one underlying condition } & Initial & \multirow{2}{*}{$130 / 317$} & \multirow{2}{*}{$499 / 892$} & 35.7 & 11.4 to 53.3 \\
\hline & Initial plus severity & & & 35.6 & 11.2 to 53.3 \\
\hline \multicolumn{6}{|l|}{ Diabetes mellitus } \\
\hline No & Initial & $98 / 242$ & $370 / 674$ & 33.9 & 4.6 to 54.2 \\
\hline \multirow{2}{*}{ Yes } & Initial & \multirow{2}{*}{$33 / 96$} & \multirow{2}{*}{$150 / 266$} & 58.5 & 22.8 to 77.7 \\
\hline & Initial plus severity & & & 58.5 & 22.7 to 77.8 \\
\hline \multicolumn{6}{|l|}{ Heart disease } \\
\hline No & Initial & $54 / 131$ & $207 / 372$ & 37.3 & -1.2 to 61.1 \\
\hline \multirow{2}{*}{ Yes } & Initial & \multirow{2}{*}{$80 / 211$} & \multirow{2}{*}{$321 / 581$} & 38.4 & 6.5 to 59.5 \\
\hline & Initial plus severity & & & 39.0 & 7.3 to 59.9 \\
\hline \multicolumn{6}{|l|}{ Lung disease } \\
\hline No & Initial & $61 / 203$ & $250 / 515$ & 39.7 & 8.0 to 60.4 \\
\hline \multirow{2}{*}{ Yes } & Initial & \multirow{2}{*}{$72 / 139$} & \multirow{2}{*}{$276 / 434$} & 42.4 & 7.2 to 64.3 \\
\hline & Initial plus severity & & & 42.8 & 7.8 to 64.5 \\
\hline \multicolumn{6}{|l|}{ Cancer } \\
\hline No & Initial & $93 / 252$ & $375 / 691$ & $35 \cdot 7$ & 6.7 to 55.7 \\
\hline \multirow{2}{*}{ Yes } & Initial & \multirow{2}{*}{$41 / 90$} & \multirow{2}{*}{$150 / 256$} & 47.7 & 4.8 to 71.3 \\
\hline & Initial plus severity & & & 47.8 & 4.8 to 71.4 \\
\hline \multicolumn{6}{|l|}{ Vaccine type } \\
\hline Inactivated subunit & Initial & $77 / 224$ & $209 / 538$ & 28.1 & -8.6 to 52.4 \\
\hline Inactivated split virion & Initial & $59 / 178$ & $312 / 588$ & 54.7 & 30.7 to 70.4 \\
\hline \multicolumn{6}{|l|}{ Sensitivity analyses } \\
\hline Two-stage model & two-stage $^{\mathrm{b}}$ & $132 / 329$ & $527 / 932$ & 49.0 & 13.5 to 70.0 \\
\hline $\begin{array}{l}\text { Restricted to patients swabbed within } \\
3 \text { days }\end{array}$ & Initial & $85 / 216$ & $313 / 518$ & 49.1 & 23.8 to 66.0 \\
\hline $\begin{array}{l}\text { Restricted to patients not receiving } \\
\text { antivirals before swabbing }\end{array}$ & Initial & $126 / 317$ & $531 / 940$ & 42.2 & 20.8 to 57.8 \\
\hline
\end{tabular}

$\mathrm{Cl}$ : confidence interval; I MOVE+: Integrated Monitoring of Vaccines in Europe plus; IVE: influenza vaccine effectiveness.

a Initial: one-stage model adjusted for study site, date of symptom onset and age (modelled as restricted cubic splines). Full: one-stage model adjusted for study site, date of symptom onset, age (modelled as restricted cubic splines), lung, heart, renal disease, diabetes mellitus, cancer, obesity (body-mass index $\geq 30 \mathrm{~kg} / \mathrm{m}^{2}$ ) and hospitalisation for underlying conditions in past year. Severity: hospitalisations for underlying conditions in the previous year.

${ }^{b}$ Poland and Hungary were excluded because there were no vaccinated controls in Poland and no cases in Hungary.

countries with at least one patient vaccinated with a specific type.

We also computed a pooled IVE with a two-stage model, adjusting study site-specific IVE for study site-specific confounders (same as listed above) when sample size allowed. We quantified the heterogeneity between site estimates using the I-square [23].

To minimise the inclusion of false influenza-negatives in the control group, we carried out sensitivity analyses by restricting population to (i) patients swabbed up to three days after symptom onset and (ii) patients not treated with antivirals until the day before swabbing.

\section{Results}

A total of 2,077 patients meeting the inclusion criteria were recruited in the study. We excluded 472 controls (23\%) recruited outside of the study period and 65 patients $(4 \%)$ with missing information on vaccination status. We included 1,274 controls and 528 cases, of which $353(67 \%)$ were influenza $A\left(\mathrm{H}_{1} \mathrm{~N}_{1}\right)$ pdmog positive, 105 (20\%) were influenza B-positive, 41 (8\%) were influenza $A\left(\mathrm{H}_{3} \mathrm{~N}_{2}\right)$-positive, 24 (5\%) were influenza $A$ (non-subtyped)-positive, two ( $<1 \%$ ) were co-infected by influenza $A\left(\mathrm{H}_{1} \mathrm{~N}_{1}\right)$ pdmog and $B$, one ( $(1 \%)$ was coinfected by influenza $A\left(\mathrm{H}_{3} \mathrm{~N}_{2}\right)$ and $B$ and two ( $\left.{ }_{1} \%\right)$ were co-infected by influenza $A$ (non-subtyped) and $B$. Of the 52 cases of influenza B with a known lineage, 47 
TABLE 4

Study site specific and two-stage ${ }^{a}$ pooled seasonal vaccine effectiveness against hospitalised influenza A(H1N1)pdm09 among elderly people, I- MOVE + study, Europe, influenza season 2015/16 ( $n=1,261)$

\begin{tabular}{|c|c|c|c|c|c|c|c|}
\hline Study site & Inclusion period & $\begin{array}{l}\text { Variables used for } \\
\text { adjustment }^{\mathrm{b}}\end{array}$ & $\begin{array}{l}\text { Vaccinated } \\
\text { /cases }\end{array}$ & $\begin{array}{l}\text { Vaccinated } \\
\text { /controls }\end{array}$ & $\begin{array}{l}\text { Adjusted } \\
\text { IVE }\end{array}$ & $95 \% \mathrm{Cl}$ & I-square \\
\hline Croatia & $2016 w 5-2016 w 13$ & Date & $4 / 16$ & $1 / 15$ & -122.0 & $-4,314.5$ to 88.8 & - \\
\hline Finland & $2015 w_{50-2016 w 7}$ & Date & $5 / 18$ & $38 / 57$ & 85.0 & 43.7 to 96.0 & - \\
\hline France & $2016 w 4-2016 w 14$ & Date & $3 / 11$ & $84 / 124$ & 83.7 & 32.2 to 96.1 & - \\
\hline Italy & 2016 w5-2016w11 & Date & $2 / 3$ & $47 / 102$ & -152.2 & $-3,081.1$ to 80.0 & - \\
\hline Lithuania & 2016W2-2016w10 & Date & $1 / 17$ & $7 / 41$ & 66.8 & -210.4 to 96.4 & - \\
\hline Navarra & $2015 w 46-2016 w 13$ & Date & $46 / 87$ & $169 / 240$ & $45 \cdot 9$ & 5.3 to 69.1 & - \\
\hline $\begin{array}{l}\text { The } \\
\text { Netherlands }\end{array}$ & $2015 w 50-2016 w 7$ & Date & $1 / 5$ & $10 / 12$ & 94.8 & 6.9 to 99.7 & - \\
\hline Portugal & $2015 w 51-2016 w 8$ & Date, cancer, obesity & $3 / 14$ & $14 / 35$ & 11.9 & -372.7 to 83.6 & - \\
\hline Romania & $2016 w 3-2016 w 14$ & $\begin{array}{l}\text { Date, cancer, renal } \\
\text { disease }\end{array}$ & $4 / 58$ & $6 / 100$ & -22.6 & -490.3 to 74.6 & - \\
\hline Spain & $2016 w 1-2016 w 14$ & $\begin{array}{c}\text { Date, age, heart } \\
\text { disease, dependency }\end{array}$ & $63 / 100$ & $151 / 206$ & 22.5 & -39.6 to 56.9 & - \\
\hline $\begin{array}{l}\text { two-stage } \\
\text { pooled }\end{array}$ & - & - & - & - & $49 \cdot 0$ & 13.5 to 70.0 & $36.2 \%$ \\
\hline
\end{tabular}

$\mathrm{Cl}$ : confidence interval; I MOVE+: Integrated Monitoring of Vaccines in Europe plus; IVE: influenza vaccine effectiveness; w: week (International Organisation for Standardisation (ISO) week).

a Poland and Hungary were excluded from the two-stage analyses because there were no vaccinated controls in Poland and no cases in Hungary.

${ }^{b}$ Date of symptom onset and age modelled as restricted cubic spline with four knots.

(90\%) were Victoria and $5(10 \%)$ were Yamagata. The 42 cases positive for influenza $\mathrm{A}\left(\mathrm{H}_{3} \mathrm{~N}_{2}\right)$ did not allow us to compute IVE against this subtype.

The maximum number of influenza $A\left(\mathrm{H}_{1} \mathrm{~N}_{1}\right)$ pdmog cases were recruited in weeks 5 to 8 of 2016 and the maximum number of influenza $B$ and $A\left(\mathrm{H}_{3} \mathrm{~N}_{2}\right)$ cases in week 10 (Figure 2).

Overall, $216 / 528$ cases (41\%) and 694/1,274 controls (54\%) had received trivalent inactivated vaccines. Among those vaccinated, 51 (6\%) received adjuvanted vaccines, $338(37 \%)$ inactivated subunit vaccines, 513 (56\%) inactivated split virion vaccines and the information on vaccine type was missing for $8(1 \%)$ vaccinated patients. Age and time adjusted IVE against any influenza was 39\% (95\% confidence interval (Cl): 22 to 53 ).

\section{Vaccine effectiveness against hospitalised influenza $\mathrm{A}(\mathrm{H} 1 \mathrm{N1}) \mathrm{pdim} 09$}

We included in this analysis 355 cases of influenza $A\left(\mathrm{H}_{1} \mathrm{~N}_{1}\right)$ pdmo9, of whom $138(39 \%)$ were vaccinated, and 976 controls, of whom $543(56 \%)$ vaccinated. The median age of $A\left(\mathrm{H}_{1} \mathrm{~N}_{1}\right)$ pdmog cases and controls was 76 (Interquartile range $(\mathrm{IQR})=12$ years) and $78(\mathrm{IQR}$ $=12$ years) years respectively $(p=0.001)$. The proportion of patients with underlying conditions was similar among cases and controls except for renal (16\% among cases vs $23 \%$ among controls, $p=0.003$ ) and rheumatologic diseases ( $6 \%$ among cases vs $11 \%$ among controls, $p=0.033)$. Ten percent of $A\left(\mathrm{H}_{1} \mathrm{~N}_{1}\right)$ pdmog cases and $3 \%$ of controls had received antivirals before swabbing ( $p<0.001)$ and $61 \%$ of cases vs $53 \%$ of controls were swabbed within 3 days after symptoms onset $(p=0.013)$ (Table 2).

One-stage pooled IVE against $\mathrm{A}\left(\mathrm{H}_{1} \mathrm{~N}_{1}\right)$ pdmog adjusted for onset time and age was $42 \%(95 \% \mathrm{Cl}: 22$ to 57$)$ and $39 \%(95 \% \mathrm{Cl}: 17$ to 56 ) when further adjusted for a range of underlying conditions and hospitalisation in the previous year (Table 3). IVE against $\mathrm{A}\left(\mathrm{H}_{1} \mathrm{~N}_{1}\right)$ pdmog was $59 \%$ ( $95 \% \mathrm{Cl}: 23$ to 78 ), $48 \%$ (95\% Cl: 5 to 71 ), $43 \%$ (95\% Cl: 8 to 65$)$ and $39 \%(95 \% \mathrm{Cl}: 7$ to 60 ) in patients with diabetes mellitus $(n=362)$, cancer $(n=346)$, lung $(n=573)$ and heart disease $(n=792)$, respectively (Table 3).

IVE against $\mathrm{A}\left(\mathrm{H}_{1} \mathrm{~N}_{1}\right)$ pdmog was $28 \%(95 \% \mathrm{Cl}$ : -9 to 52) for inactivated subunit vaccines $(n=762)$ and $55 \%$ (95\% Cl: 31 to 70 ) for inactivated split virion vaccines $(n=716)$.

Study site specific IVE ranged between $-152 \%(95 \% \mathrm{Cl}$ : $-3,081$ to 80$)$ in Italy $(n=105)$ and $95 \%(95 \% \mathrm{Cl}: 7$ to $100)$ in the Netherlands $(n=17)$ (Table 4$)$. The statistical heterogeneity between study site specific IVE estimates was moderate $(12=36 \%)$. The two-stage pooled analysis $(n=1,261)$ included Croatia, Finland, France, Italy, Lithuania, Navarre, the Netherlands, Portugal, Romania and Spain. IVE was $49 \%$ (95\% Cl: 14 to 70 ). In sensitivity analyses, IVE against influenza $\mathrm{A}\left(\mathrm{H}_{1} \mathrm{~N}_{1}\right)$ pdmog was $42 \%$ (95\% Cl: 21 to 58) when restricting to patients not having received antiviral treatment $(\mathrm{n}=1,257)$ and $49 \%(95 \% \mathrm{Cl}: 24$ to 66$)$ among patients 
TABLE 5

Pooled adjusted seasonal vaccine effectiveness against hospitalised influenza B among elderly people overall and by risk groups, I-MOVE + study, Europe, influenza season 2015/16

\begin{tabular}{|c|c|c|c|c|c|}
\hline & $\begin{array}{l}\text { Model used for } \\
\text { adjustment }^{\mathrm{a}}\end{array}$ & $\begin{array}{l}\text { Vaccinated } \\
\text { /cases }\end{array}$ & $\begin{array}{l}\text { Vaccinated } \\
\text { /controls }\end{array}$ & Adjusted IVE & $95 \% \mathrm{Cl}$ \\
\hline \multicolumn{6}{|l|}{ Overall } \\
\hline Overall & Initial & $50 / 110$ & $588 / 1,015$ & 51.8 & 23.7 to 69.5 \\
\hline Overall & Full & $46 / 101$ & $544 / 948$ & 47.0 & 13.1 to 67.7 \\
\hline \multicolumn{6}{|l|}{ By risk groups } \\
\hline \multirow{2}{*}{ At least one underlying condition } & Initial & \multirow{2}{*}{$47 / 97$} & \multirow{2}{*}{$536 / 929$} & 50.2 & 18.7 to 69.4 \\
\hline & Initial plus severity & & & 49.4 & 17.5 to 69.0 \\
\hline \multicolumn{6}{|l|}{ Diabetes mellitus } \\
\hline No & Initial & $33 / 72$ & $404 / 696$ & 40.9 & -7.1 to 67.4 \\
\hline \multirow{2}{*}{ Yes } & Initial & \multirow{2}{*}{$13 / 30$} & \multirow{2}{*}{$152 / 272$} & 62.1 & 5.8 to 84.7 \\
\hline & Initial plus severity & & & 62.0 & 5.3 to 84.8 \\
\hline \multicolumn{6}{|l|}{ Heart disease } \\
\hline No & Initial & $16 / 44$ & $211 / 368$ & 66.5 & 27.6 to 84.5 \\
\hline \multirow{2}{*}{ Yes } & Initial & \multirow{2}{*}{$32 / 61$} & \multirow{2}{*}{$354 / 614$} & 36.3 & -22.2 to 66.8 \\
\hline & Initial plus severity & & & 36.1 & -22.9 to 66.7 \\
\hline \multicolumn{6}{|l|}{ Lung disease } \\
\hline No & Initial & $27 / 61$ & $258 / 502$ & 32.8 & -28.6 to 64.8 \\
\hline \multirow{2}{*}{ Yes } & Initial & \multirow{2}{*}{$22 / 45$} & \multirow{2}{*}{$305 / 475$} & 60.5 & 19.2 to 80.6 \\
\hline & Initial plus severity & & & 59.9 & 18.2 to 80.4 \\
\hline \multicolumn{6}{|l|}{ Vaccine type } \\
\hline Inactivated subunit & Initial & $20 / 61$ & $207 / 542$ & 49.0 & 13.5 to 70.0 \\
\hline Inactivated split virion & Initial & $30 / 74$ & $332 / 652$ & 54.1 & 18.9 to 74.0 \\
\hline \multicolumn{6}{|l|}{ Sensitivity analyses } \\
\hline two-stage model & two-stage $^{b}$ & $48 / 86$ & $551 / 858$ & 47.0 & 11.9 to 68.2 \\
\hline $\begin{array}{l}\text { Restricted to patients swabbed } \\
\text { within } 3 \text { days }\end{array}$ & Initial & $31 / 54$ & $358 / 585$ & 25.0 & -50.5 to 62.6 \\
\hline $\begin{array}{l}\text { Restricted to patients not receiving } \\
\text { antivirals before swabbing }\end{array}$ & Initial & $46 / 99$ & $577 / 985$ & 52.3 & 22.8 to 70.5 \\
\hline
\end{tabular}

$\mathrm{Cl}$ : confidence interval; I MOVE+: Integrated Monitoring of Vaccines in Europe plus; IVE: influenza vaccine effectiveness.

${ }^{a}$ Initial: one-stage model adjusted for study site, date of onset and age (modelled as restricted cubic splines). Full: one-stage model adjusted for study site, date of symptom onset, age (modelled as restricted cubic splines), lung, heart, renal disease, diabetes mellitus, cancer, obesity and hospitalisation in the previous year Severity: hospitalisations for underlying conditions in the previous year.

${ }^{b}$ Croatia, Hungary, Italy, Lithuania, the Netherlands, Poland, Portugal and Romania were excluded from the two-stage analyses because there were no vaccinated controls and/or cases, respectively.

swabbed within 3 days of symptoms onset $(n=734)$ (Table 3).

\section{Vaccine effectiveness against hospitalised influenza B}

We included in this analysis 110 cases of influenza $B$, of whom 50 (46\%) were vaccinated and 1,015 controls, of whom 588 (58\%) vaccinated. The median age of cases and controls were 76 (IQR: 12 years) and 78 years (IQR: 12 years) respectively $(p=0.056)$. A lower proportion of cases than controls had cancer ( $18 \%$ vs $28 \%, p=0.037$ ), a functional impairment (18\% vs $36 \%$, $\mathrm{p}<0.001)$, and had been hospitalised in the previous 12 months ( $36 \%$ vs $48 \%, p=0.02$ ). The proportion of current smokers was higher among influenza $B$ cases than among controls ( $35 \%$ vs $23 \%, p=0.007$ ) (Table 2 ).
One stage pooled IVE against influenza B adjusted for symptom onset time and age was 52\% (95\% Cl: 24 to $70)$ and $47 \%(95 \% \mathrm{Cl}: 13$ to 68) when further adjusted for a range of underlying conditions and hospitalisation in the previous year (Table 5). IVE was 62\% (95\% Cl: 5 to 85 ), $60 \%$ (95\% Cl: 18 to 80 ) and $36 \%(95 \% \mathrm{Cl}:-23$ to 67$)$ in patients with diabetes mellitus $(n=302)$, lung $(n=520)$ and heart disease $(n=675)$, respectively.

IVE against influenza B was $49 \%(95 \% \mathrm{Cl}: 14$ to 70$)$ for inactivated subunit vaccines $(n=603)$ and $54 \%$ (95\% Cl: 19 to 74 ) for inactivated split virion vaccines $(n=726)$.

Study site specific IVE ranged between 18\% (95\% Cl: -106 to 67$)$ in Finland $(\mathrm{n}=38)$ and $76 \%(95 \% \mathrm{Cl}:-24$ to 95$)$ in Italy $(n=259)$ (Table 6$)$. There was no statistical heterogeneity between study site specific IVE 
Study site-specific and two-stage ${ }^{a}$ pooled seasonal vaccine effectiveness against hospitalised influenza B among elderly people, I- MOVE + study, Europe, influenza season 2015/16

\begin{tabular}{|c|c|c|c|c|c|c|c|}
\hline Study site & Inclusion period & $\begin{array}{l}\text { Variables used for } \\
\text { adjustment }^{\mathrm{b}}\end{array}$ & $\begin{array}{l}\text { Vaccinated } \\
\text { /cases }\end{array}$ & $\begin{array}{l}\text { Vaccinated } \\
\text { /controls }\end{array}$ & Adjusted IVE & $95 \% \mathrm{Cl}$ & I-square \\
\hline Finland & $2016 w 8-2016 w 15$ & Date & $2 / 3$ & $22 / 35$ & 23.3 & $-1,785.9$ to 96.9 & - \\
\hline France & 2016W4-2016W14 & $\begin{array}{l}\text { Date, age, functional } \\
\text { impairment }\end{array}$ & $17 / 26$ & $87 / 120$ & 18.1 & -105.6 to 67.4 & - \\
\hline Italy & 2016W1-2016w12 & Date & $2 / 10$ & $121 / 249$ & $75 \cdot 5$ & -23.7 to 95.1 & - \\
\hline Navarre & 2015 W53-2016w17 & Date & $17 / 27$ & $165 / 230$ & 59.4 & -2.5 to 83.9 & - \\
\hline Spain & $2016 w 2-2016 w 16$ & $\begin{array}{c}\text { Date, lung disease, } \\
\text { dependency }\end{array}$ & $11 / 20$ & $159 / 220$ & $44 \cdot 3$ & -48.9 to 79.1 & - \\
\hline $\begin{array}{l}\text { two-stage } \\
\text { pooled } \\
(\mathrm{n}=944)\end{array}$ & - & - & - & - & 47.0 & 11.9 to 68.2 & $0.0 \%$ \\
\hline
\end{tabular}

$\mathrm{Cl}$ : confidence interval; I MOVE+: Integrated Monitoring of Vaccines in Europe plus; IVE: influenza vaccine effectiveness; w: week (International Organisation for Standardisation (ISO) week).

${ }^{a}$ Croatia, Hungary, Italy, Lithuania, the Netherlands, Poland, Portugal and Romania were excluded from the two-stage analyses because there were no vaccinated controls and/or cases.

${ }^{b}$ Date of onset and age modelled as restricted cubic spline with four knots.

estimates $(12=0 \%)$. The two-stage pooled analysis $(n=944)$ included Finland, France, Italy, Navarre and Spain. IVE was $47 \%$ (95\% Cl: 12 to 68$)$. In sensitivity analyses, IVE against influenza B was 52\% (95\% Cl: 23 to 71 ) when restricting to patients not having received antiviral treatment $(\mathrm{n}=1,084)$ and $25 \%(95 \% \mathrm{Cl}:-51$ to 63) among patients swabbed within 3 days of symptoms onset $(n=639)$.

\section{Discussion}

Our results suggest that the seasonal IVE against hospitalised influenza among elderly people was moderate during the 2015/16 influenza season in Europe for influenza: $39 \%$ overall, $42 \%$ against influenza $A\left(\mathrm{H}_{1} \mathrm{~N}_{1}\right)$ pdmog and $52 \%$ against influenza B. These estimates did not vary between categories of underlying conditions.

Data from European virological surveillance reported that most of the characterised influenza $A\left(\mathrm{H}_{1} \mathrm{~N}_{1}\right)$ pdmog viruses belonged to the emerging subclade 6B.1, defined by haemagglutinin amino acid substitutions S162N and I216T [18]. Despite these genetic evolutions, $\mathrm{A}\left(\mathrm{H}_{1} \mathrm{~N}_{1}\right)$ pdmog viruses were considered antigenically similar to the northern hemisphere vaccine component A/California/7/2009. IVE estimates against hospitalised $A\left(\mathrm{H}_{1} \mathrm{~N}_{1}\right)$ pdmog was consistent with the results we reported in 2012/13 and 2013/14 among hospitalised elderly people $[24,25]$.

In 2015/16, the circulating influenza B Victoria lineage was distinct from the Yamagata vaccine component [26] and there was no quadrivalent vaccine used in our study population. IVE against influenza B was close to what we reported, using the same generic protocol, in $2012 / 13$ (66\% in the $65-79$ year-olds and $44 \%$ in the 80 year-olds and older) in a season with co-circulation of B Victoria and Yamagata lineages and a Yamagata vaccine component $[24,27]$. These results suggest some cross-lineage protection and they are in line with previously reported data in GP-based studies $[28,29]$ and a meta-analysis of eight randomised controlled trials with mismatched $B$ viruses resulting in a VE of $52 \%$ (95\% Cl: 19 to 72 ) among healthy adults [30]. Further studies are needed to increase the understanding of mechanisms of cross-lineage protection for influenza $\mathrm{B}$ and better guide policy makers in terms of recommendations for using trivalent or tetravalent seasonal vaccines.

We observed higher point estimates of IVE for the inactivated split virion vaccines compared with inactivated subunit vaccines, although the $95 \% \mathrm{Cls}$ of the point estimates were widely overlapping. The completeness of data on vaccine type was high ( $1 \%$ of missing vaccine type among those vaccinated), thus these results, concurring with published data [31-33], could be due to differences in $\mathrm{T}$-cell responses conferred by the two vaccine types [34]. However, they should be interpreted with caution as they may be due to random variation. Further evidence, and pooling of several years of data would be required to obtain precise vaccine type specific effectiveness. Higher adjuvant vaccine coverage would be needed to compute adjuvant vaccine specific IVE. This would be useful information to adapt influenza vaccination strategies among elderly people.

Recent reviews underlined the need for further evidence of seasonal IVE against laboratory-confirmed influenza in elderly people and patients with underlying conditions [8-13]. We were able to collect high quality data from 1,802 elderly patients hospitalised with SARI, making our study one of the largest hospitalbased studies on IVE. The large number of participants, 
and a vaccine coverage close to $50 \%$, enabled us to compute IVE against type/subtype-specific influenza among patients with specific underlying conditions. Our results suggest that, in 2015/16, the seasonal influenza vaccine provided protection against hospitalised influenza $A\left(\mathrm{H}_{1} \mathrm{~N}_{1}\right)$ pdmog and $B$ in the elderly with diabetes mellitus, heart and lung disease. We were unable to refine the underlying conditions categories further. To better guide vaccine recommendations, IVE among patients receiving specific treatment (e.g. statins $[35,36]$, chemotherapy $[9,37]$ ) or with more specific conditions (e.g. asthma, chronic obstructive pulmonary disease) would be needed. A larger sample size would be required for such studies.

We collected information related to access to care, health conditions and smoking status. Recruited cases and controls were similar. We adjusted our estimates for study site, onset week and age. Further adjustment for potential confounders (underlying lung, heart, renal disease, diabetes mellitus, cancer, obesity and hospitalisations in the past year) did not change the estimates. However, as in any observational study, we cannot exclude unmeasured confounding leading to over- or under-estimation of the IVE.

The contribution to the pooled dataset was different between study sites. The two Spanish sites recruited $44 \%$ of the patients. The viruses circulating and vaccines used in Spain were similar to the other countries. Consequently we do not expect the over-representation of Spanish sites to have biased our overall estimates. Variations in the number of recruited individuals may be explained by differences in local influenza activity or number and size of participating hospitals/ services. We believe that access to hospitalisation in case of severe influenza is similar across participating European countries. A common generic protocol and the monitoring of its implementation through on-site visits contributed to ensuring comparability of patients recruited and data collected across study sites. We measured low statistical heterogeneity based on I-square values. However, small number of estimates and large study-specific Cls may hinder adequate quantitative assessment of heterogeneity between studies [38]. True differences between study site specific IVE could be related to different vaccines used during this season or different immunological profiles of recruited patients including their past vaccination histories [39]. Larger study site-specific sample sizes are required to ensure that the differences in IVE across study sites are not due to chance. Currently, multicentre studies are necessary to obtain precise IVE estimates.

A recent publication by Foppa et al. suggested that measuring IVE against laboratory-confirmed influenza SARI hospitalisation using the TND was subject to biases if the test-negative controls were hospitalised because of an exacerbation of underlying lung disease unrelated to a respiratory infection [40]. In our study, cases and controls had similar prevalence of underlying lung disease. Underlying lung disease did not appear to confound IVE estimates, even when combined with a proxy of its severity (hospitalisation because of underlying conditions in the past 12 months). Cohort and TND-based IVE estimates against laboratory-confirmed hospitalised influenza in Navarre repeatedly showed similar estimates, reassuring on the appropriateness of TND at hospital level [41].

Several studies suggest that past influenza vaccinations may decrease or enhance current vaccine effectiveness depending on previous and current vaccine and circulating strains as well as past exposure to the virus $[24,32,42-44]$. A large proportion of our vaccinated population had been vaccinated in the previous season(s) but the very small number of patients with varying repeated vaccination status over the years did not allow us to measure the effect of previous vaccinations. To understand the effect of repeated vaccinations on IVE, large cohorts of individuals with different vaccination patterns and symptomatic (and asymptomatic) influenza infection status over the years would be needed.

\section{Conclusion}

Our multicentre test-negative case-control study estimated that in 2015/16 the seasonal influenza vaccination prevented approximately half of the cases of hospitalisation with laboratory-confirmed influenza among vaccinated elderly people. Our results suggest that vaccination provided similar protection to elderly patients with underlying diabetes mellitus, cancer, lung and heart diseases. Because vaccination remains the most effective preventive measure against severe influenza among elderly people, increasing the vaccine coverage in this group should be a priority. This pilot season of the hospital-based I-MOVE + project proved that obtaining precise estimates of IVE against a severe influenza outcome among elderly people was feasible. Enlarging our network and its sample size will enable us to better guide vaccination strategies against severe influenza cases by comparing the performance of different vaccine types and identifying risk groups for poor response to vaccination.

\section{I-MOVE + hospital working group}

\section{EpiConcept: Alain Moren}

Spain: Jone M. Altzibar, Ion García Arraras (Subdirección de Salud Pública de Gipuzkoa, CIBERESP, Basque Country, Spain), Gustavo Cilla (Donostia University Hospital, CIBERES, San Sebastian, Basque Country, Spain), Elisa Marco (Dirección General de Salud Pública, Aragón, Spain), Matxalen Vidal, Manuel Omeñaca (Miguel Servet University Hospital, Zaragoza, Spain)

Navarra: J. Castilla (Instituto de Salud Pública de Navarra, IdiSNA, CIBERESP, Pamplona), A Navascués, C Ezpeleta (Complejo Hospitalario de Navarra, IdiSNA, Pamplona, Spain), L Barrado (Hospital de Estella, Spain), MT Ortega (Hospital de Tudela, Spain) 
Italy: A. Bella, M.R. Castrucci, S. Puzelli (Istituto Superiore di Sanità, Rome), M.Chironna, C. Germinario (Policlicnico Hospital, University of Bari); F. Ansaldi, A. Orsi (IRCCS AOU San Martino- IST, Genoa hospital); I. Manini, E. Montomoli (Department of Molecular and Developmental Medicine, University of Siena)

Romania: E.Lupulescu, M.Lazar, CM Cherciu, C. Tecu, ME Mihai (National Institute of Research Cantacuzino), M. Nitescu (INBI Matei Bals, Bucharest), D. Leca (UMF Gr. Popa Iasi), E. Ceausu (UMF Carol Davila Bucharest, Infectious Diseases Hospital V. Babes, Bucharest)

France: N. Lenzi, Z. Lesieur (Innovative clinical research network in vaccinology (I-REIVAC), P. Loulergue (Inserm, CIC Cochin-Pasteur, I-REIVAC, Paris), V. Foulongne, F. Letois, C. Merle (CHU de Montpellier, I-REIVAC), P. Vanhems (Hôpital Edouard Herriot, Lyon, I-REIVAC), B. Lina (Université Lyon 1, Centre National de Référence virus influenza France Sud, Lyon, France)

Finland: H. Nohynek, A. Haveri (National Institute for Health and Welfare)

Lithuania: M. Kuliese, D. Velyvyte (Department of Infectious Diseases of Lithuanian University of Health Sciences, Kaunas, Lithuania), R. Grimalauskaite, G. Damuleviciene, V. Lesauskaite (Department of Geriatrics, Lithuanian University of Health Sciences, Kaunas, Lithuania), L. Jancoriene, B. Zablockiene, A. Ambrozaitis (Clinic of Infectious, Chest Diseases, Dermatovenerology and Allergology, Vilnius University Faculty of Medicine, Vilnius, Lithuania)

Portugal: B. Nunes, A.P. Rodrigues (National Health Institute Doutor Ricardo Jorge, Lisbon), V. Gomes, R. Côrte-Real (Centro Hospitalar de Lisboa Central, Lisbon), J. Poças, M.J. Peres (Centro Hospitalar de Setúbal, Setúbal)

Croatia: B. Kaić (Croatian Institute of Public Health, Zagreb)

Hungary: B. Oroszi (Office of the Chief Medical Officer, Budapest)

Poland: L.B. Brydak, K. Cieślak, D. Kowalczyk, K. Szymański (National institute of Public Health - National Institute of Hygiene, Warsaw), A. Jakubik (Szpital Praski, Warsaw), G. Skolimowska (Mazovia Regional Hospital, Siedlce), D. Hulbój (Regional hospital, Bielsko-Biała)

The Netherlands: A. Meijer, W. van der Hoek (National Institute for Public Health and the Environment (RIVM), Bilthoven), P.M. Schneeberger (Jeroen Bosch Hospital, 's Hertogenbosch)

\section{Acknowledgements}

The I-MOVE+ project has received funding from the European Union's Horizon 2020 research and innovation programme under grant agreement No 634446.

The Lithuanian I-MOVE+ study sites were supported by a grant from the Research Council of Lithuania (SEN-03/2015). We are grateful to all patients, medical staff, study nurses and epidemiologists from the 12 study sites who actively participated in the study.

\section{EpiConcept: Esther Kissling}

Italy: Anna Pina Palmieri, Stefania Giannitelli and Alessia Ranghiasci (Istituto Superiore di Sanità, Rome, Italy).
Romania: Rodica Bacruban, Delia Azamfire, Aura Dumitrescu, Elena Ianosik (INBI Matei Bals), Elena Duca, Codrina Bejan, Andra Teodor (Infectious Diseases Hospital Sf. Parascheva, Iasi), Simin-Aysel Florescu, Corneliu Popescu, Gratiela Tardei, (UMF Carol Davila Bucharest, Infectious Diseases Hospital V. Babes, Bucharest, Romania)

France: Julien Charpentier, Nathalie Marin (Service de réanimation médicale, Cochin-Pasteur, APHP, Université Paris Descartes, Sorbonne Paris Cité, Paris, France), Benoit Doumenc (Service des urgences, Cochin-Pasteur, APHP, Université Paris Descartes, Sorbonne Paris Cité, Paris, France), Claire Le jeunne (Service de médecine Interne, Cochin-Pasteur, APHP, Université Paris Descartes, Sorbonne Paris Cité, Paris, France), Anne Krivine (Service de virologie, Cochin-Pasteur, APHP, Université Paris Descartes, Sorbonne Paris Cité, Paris, France), Sonia Momcilovic: CIC CochinPasteur, APHP, Université Paris Descartes, Sorbonne Paris Cité, Paris, France), Thomas BENET (Infection Control and Epidemiology Unit, Hôpital Edouard Herriot, Lyon), Sélilah AMOUR (Infection Control and Epidemiology Unit, Hôpital Edouard Herriot, Lyon), Laetitia HENAFF (Infection Control and Epidemiology Unit, Hôpital Edouard Herriot, Lyon).

Finland: Jukka Jokinen, Outi Lyytikäinen and Arto Palmu (study design, protocol writing), Päivi Sirén (clinical data collection), Esa Ruokokoski (data management), The laboratory staff in Viral Infections Unit of THL, Tampere University Hospital, Hatanpää Hospital (collaboration with the clinical work and data collection).

Portugal: Baltazar Nunes, Ana Paula Rodrigues, Raquel Guiomar (Infectious Diseases Department, National Health Institute Doutor Ricardo Jorge, Lisbon, Portugal), Victor Gomes, Filipa Quaresma, Luis Vale, Teresa Garcia, Teresa Bernardo, Liliana Dias, Paula Fonseca, Helena Amorim, João Rolo, Helena Pacheco, Paula Branquinho, Rita Côrte-Real (Centro Hospitalar de Lisboa Central, Lisbon, Portugal),José Poças, Paula Lopes, Maria João Peres, Rosa Ribeiro, Paula Duarte, Ermelinda Pedroso, Sara Rodrigues, Ana Rita Silvério, Diana Gomes Pedreira, Marta Ferreira Fonseca, (Centro Hospitalar de Setúbal, Setúbal, Portugal).

Croatia: Adriana Vince, Antea Topić, Neven Papić, Jelena Budimir Mihalić (all from the University Hospital for Infectious Diseases 'Dr. Fran Mihaljević', Zagreb), Iva Pem Novosel, Goranka Petrović, Martina Zajec, Vladimir Draženović (all from the Croatian Institute of Public Health, Zagreb).

Hungary: Éva Hercegh, Bálint Szalai (Influenza Virus Laboratory, National Center for Epidemiology, Budapest, Hungary), Katalin Antmann (Hospital Hygiene Department, Semmelweis University, Budapest, Hungary), Kamilla Nagy, (Hospital Hygiene Department, University of Szeged, Szeged, Hungary)

\section{Conflict of interest}

None declared.

\section{Authors' contributions}

Marc Rondy was involved in the original methodological design of the study (generic protocol). He coordinated the European hospital IVE network, undertook the statistical analysis on which the research article is based and led the writing of the research article.

Marta Valenciano initiated the original methodological design of the study. She coordinated the European hospital 
IVE network and contributed to the writing of the research article.

Amparo Larrauri, Itziar Casado, Valeria Alfonsi, Daniela Pitigoi, Odile Launay, Ritva S. Syrjänen, Giedre Gefenaite, Ausenda Machado, Vesna Višekruna Vučina, Judith Krisztina Horváth, Iwona Paradowska-Stankiewicz, Sierk D. Marbus, Alin Gherasim, Jorge Alberto Díaz-González, Caterina Rizzo, Alina E. Ivanciuc, Florence Galtier, Niina Ikonen, Aukse Mickiene, Veronica Gomez, Sanja Kurečić Filipović, Annamária Ferenczi, Monika R. Korcinska and Rianne van Gageldonk-Lafeber were responsible for the coordination of the study at the local level. They were in charge of the data collection and management. They read, contributed and approved the manuscript final version.

The I-MOVE+ hospital working group contributors contributed to developing the study site specific protocol. They were in charge of supervising the study at the hospital level and collect the data published in this research article. They read, contributed and approved the manuscript final version.

\section{References}

1. Mertz D, Kim TH, Johnstone J, Lam P-P, Science M, Kuster SP, et al. Populations at risk for severe or complicated influenza illness: systematic review and meta-analysis. BMJ. 2013;347(aug23 1):f5061.

2. Hewitt R, Farne H, Ritchie A, Luke E, Johnston SL, Mallia $P$. The role of viral infections in exacerbations of chronic obstructive pulmonary disease and asthma. Ther Adv Respir Dis. 2016;10(2):158-74. DOI: 10.1177/1753465815618113 PMID: 26611907

3. Rothberg MB, Haessler SD, Brown RB. Complications of viral influenza.Am J Med. 2008;121(4):258-64. DOI: 10.1016/j. amjmed.2007.10.040 PMID: 18374680

4. Kunisaki KM, Janoff EN. Influenza in immunosuppressed populations: a review of infection frequency, morbidity, mortality, and vaccine responses.Lancet Infect Dis. 2009;9(8):493-504. DOI: 10.1016/S1473-3099(09)70175-6 PMID: 19628174

5. Muller LM, Gorter KJ, Hak E, Goudzwaard WL, Schellevis FG, Hoepelman Al, et al. Increased risk of common infections in patients with type 1 and type 2 diabetes mellitus. Clin Infect Dis. 2005;41(3):281-8. DOI: 10.1086/431587 PMID: 16007521

6. Frasca D, Diaz A, Romero M, Mendez NV, Landin AM, Ryan JG, et al. Young and elderly patients with type 2 diabetes have optimal $B$ cell responses to the seasonal influenza vaccine. Vaccine. 2013;31(35):3603-10. DOI: 10.1016/j. vaccine.2013.05.003 PMID: 23711934

7. Muszkat M, Friedman G, Dannenberg HD, Greenbaum E, Lipo $M$, Heymann $Y$, et al. Response to influenza vaccination in community and in nursing home residing elderly: relation to clinical factors. Exp Gerontol. 2003;38(10):1199-203. DOI: 10.1016/j.exger.2003.07.004 PMID: 14580873

8. Jefferson T, Di Pietrantonj C, Al-Ansary LA, Ferroni E, Thorning $S$, Thomas RE. Vaccines for preventing influenza in the elderly. Cochrane Database Syst Rev. 2010; (2):CDoo4876.PMID: 20166072

9. Eliakim-Raz N, Vinograd I, Zalmanovici Trestioreanu A, Leibovici L, Paul M. Influenza vaccines in immunosuppressed adults with cancer.Cochrane Database Syst Rev. 2013; (10):CDoo8983.PMID: 24166741

10. Remschmidt C, Wichmann 0 , Harder T. Vaccines for the prevention of seasonal influenza in patients with diabetes: systematic review and meta-analysis.BMC Med. 2015;13(1):53 DOI: $10.1186 /$ s12916-015-0295-6 PMID: 25857236

11. Cates CJ, Rowe BH. Vaccines for preventing influenza in people with asthma.Cochrane Database Syst Rev. 2013; (2):CDo00364. PMID: 23450529

12. Poole PJ, Chacko E, Wood-Baker RWB, Cates CJ. Influenza vaccine for patients with chronic obstructive pulmonary disease.Cochrane Database Syst Rev. 2006; (1):CDo02733. PMID: 16437444

13. Clar C, Oseni Z, Flowers N, Keshtkar-Jahromi M, Rees K. Influenza vaccines for preventing cardiovascular disease. Cochrane Database Syst Rev. 2015; (5):CD005050.PMID: 25940444

14. Council of the European Union. Council recommendation of 22 December 2009 on seasonal influenza vaccination. Official
Journal of the European Union. Luxembourg: Publications Office of the European Union; 2009. http://eur-lex.europa.eu/ legal-content/EN/TXT/HTML/?uri=CELEX:32009H1019\&from= EN

15. Vaccines against influenza WHO position paper - November 2012. Wkly Epidemiol Rec. 2012;87(47):461-76.PMID: 23210147

16. European Centre for Disease Prevention and Control (ECDC). Seasonal influenza vaccination in Europe - Overview of vaccination recommendations and coverage rates in the EU Member States for the 2012-13 influenza season. Stockholm: ECDC; Jan 2015. Available from: http://ecdc.europa.eu/en/ publications/Publications/Seasonal-influenza-vaccinationEurope-2012-13.pdf

17. World Health Organization (WHO). Recommended composition of influenza virus vaccines for use in the 2015-2016 northern hemisphere influenza season. Geneva: WHO; Feb 2015. Available from: http://www.who.int/entity/influenza/vaccines/ virus/recommendations/2015_16_north/en/index.html

18. European Centre for Disease Prevention and Control (ECDC). Influenza virus characterisation. Summary Europe. Stockholm: ECDC; Jun 2016. Available from: http://ecdc.europa.eu/en/ publications/Publications/influenza-virus-characterisationjune-2016.pdf

19. EpiConcept. Protocol for hospital-based test negative case control studies to measure seasonal influenza vaccine effectiveness against influenza laboratory confirmed SARI hospitalisation among the elderly across the European Union and European Economic Area Member States. Paris: Integrated Monitoring of Vaccines in Europe plus (I-MOVE+). [Accessed 4 May 2016]. Available from: https://drive.google.com/a/ epiconcept.fr/file/d/oB54XpZN4SY65QXFqQThQNEQ5cmM/view

20. EpiConcept. I-MOVE+ (Integrated Monitoring of Vaccines in Europe plus). Paris: I-MOVE+. [Accessed 5 Jul 2017]. http:// www.i-moveplus.eu/wp2

21. VENICE II Consortium. Seasonal influenza vaccination survey in EU/EEA, influenza season 2009-10. Final report. Rome: VENICE project; 2011 [Accessed 24 Oct 2013]. Available from: http:// venice.cineca.org/Final_Seasonal_Influenza_Vaccination_ Survey 2010.pdf

22. Mahoney FI, Barthel DW. Functional evaluation: the Barthel index.Md State Med J. 1965;14:61-5.PMID: 14258950

23. Huedo-Medina TB, Sánchez-Meca J, Marín-Martínez F, Botella J. Assessing heterogeneity in meta-analysis: $Q$ statistic or I2 index?Psychol Methods. 2006;11(2):193-206. DOI: 10.1037/1082-989X.11.2.193 PMID: 16784338

24. Rondy M, Launay O, Puig-Barberà J, Gefenaite G, Castilla J, de Gaetano Donati K, et al. 2012/13 influenza vaccine effectiveness against hospitalised influenza $\mathrm{A}\left(\mathrm{H}_{1} \mathrm{~N}_{1}\right)$ pdmog, $A\left(\mathrm{H}_{3} \mathrm{~N}_{2}\right)$ and $B$ : estimates from a European network of hospitals. Euro Surveill. 2015;20(2):21011. DOI: 10.2807/15607917.ES2015.20.2.21011 PMID: 25613779

25. Rondy M, Castilla J, Launay O, Costanzo S, Ezpeleta C, Galtier $\mathrm{F}$, et al. Moderate influenza vaccine effectiveness against hospitalisation with $A\left(\mathrm{H}_{3} \mathrm{~N}_{2}\right)$ and $A\left(\mathrm{H}_{1} \mathrm{~N}_{1}\right)$ influenza in 2013-14: Results from the InNHOVE network. Hum Vaccin Immunother. 2016;12(5):1217-24. DOI: 10.1080/21645515.2015.1126013 PMID: 27065000

26. Broberg E, Melidou A, Prosenc K, Bragstad K, Hungnes O. Predominance of influenza $A\left(\mathrm{H}_{1} \mathrm{~N}_{1}\right)$ pdmog virus genetic subclade 6B.1 and influenza B/Victoria lineage viruses at the start of the 2015/16 influenza season in Europe. Euro Surveill. 2016;21(13):30184. DOI: 10.2807/1560-7917. ES.2016.21.13.30184 PMID: 27074657

27. European Centre for Disease Prevention and Control (ECDC). Influenza virus characterisation Summary Europe. Stockholm: ECDC; Jul 2013. Available from: http://ecdc.europa.eu/en/ publications/Publications/influenza-virus-characterisationJuly-2013.pdf

28. Skowronski DM, Janjua NZ, De Serres G, Sabaiduc S, Eshaghi A, Dickinson JA, et al. Low 2012-13 influenza vaccine effectiveness associated with mutation in the eggadapted $\mathrm{H}_{3} \mathrm{~N}_{2}$ vaccine strain not antigenic drift in circulating viruses. PLoS One. 2014;9(3):e92153. DOI: 10.1371/journal. pone.0092153 PMID: 24667168

29. Skowronski DM, Janjua NZ, Sabaiduc S, De Serres G, Winter $A-L$, Gubbay JB, et al. Influenza A/subtype and B/lineage effectiveness estimates for the 2011-2012 trivalent vaccine: cross-season and cross-lineage protection with unchanged vaccine. I Infect Dis. 2014;210(1):126-37. DOI: 10.1093/infdis/ jiuo48 PMID: 24446529

30. Tricco AC, Chit A, Soobiah C, Hallett D, Meier G, Chen MH, et al. Comparing influenza vaccine efficacy against mismatched and matched strains: a systematic review and meta-analysis. BMC Med. 2013;11(1):153. DOI: 10.1186/1741-7015-11-153 PMID: 23800265 
31. Talbot HK, Nian H, Zhu Y, Chen Q, Williams JV, Griffin MR. Clinical effectiveness of split-virion versus subunit trivalent influenza vaccines in older adults. Clin Infect Dis. 2015;60(8):1170-5. DOI: 10.1093/cid/civ019 PMID: 25697739

32. Castilla J, Navascués A, Fernández-Alonso M, Reina G, Pozo F, Casado I, et al. . Effectiveness of subunit influenza vaccination in the 2014-2015 season and residual effect of split vaccination in previous seasons.Vaccine. 2016;34(11):1350-7. DOI: 10.1016/j.vaccine.2016.01.054 PMID: 26854911

33. Puig-Barberà J, García-de-Lomas J, Díez-Domingo J, ArnedoPena A, Ruiz-García M, Limón-Ramírez R, et al. Influenza vaccine effectiveness in preventing influenza $A\left(\mathrm{H}_{3} \mathrm{~N}_{2}\right)$-related hospitalizations in adults targeted for vaccination by type of vaccine: a hospital-based test-negative study, 2011-2012 $\mathrm{A}\left(\mathrm{H}_{3} \mathrm{~N}_{2}\right)$ predominant influenza season, Valencia, Spain. PLoS One. 2014;9(11):e112294. DOI: 10.1371/journal.pone.0112294 PMID: 25392931

34. Co MDT, Orphin L, Cruz J, Pazoles P, Green KM, Potts J, et al. In vitro evidence that commercial influenza vaccines are not similar in their ability to activate human $T$ cell responses. Vaccine. 2009;27(2):319-27. DOI: 10.1016/j. vaccine.2008.09.092 PMID: 18977404

35. Atmar RL, Keitel WA. Influenza Vaccination of Patients Receiving Statins: Where Do We Go From Here?] Infect Dis. 2016;213(8):1211-3. DOI: 10.1093/infdis/jiv459 PMID: 26516140

36. Black S, Nicolay U, Del Giudice G, Rappuoli R. Influence of Statins on Influenza Vaccine Response in Elderly Individuals.J Infect Dis. 2016;213(8):1224-8. DOI: 10.1093/infdis/jiv456 PMID: 26516142

37. Choi DK, Fuleihan RL, Walterhouse DO. Serologic response and clinical efficacy of influenza vaccination in children and young adults on chemotherapy for cancer.Pediatr Blood Cancer. 2016;63(11):2011-8. DOI: 10.1002/pbc.26110 PMID: 27327360

38. Rücker G, Schwarzer G, Carpenter JR, Schumacher M. Undue reliance on I(2) in assessing heterogeneity may mislead.BMC Med Res Methodol. 2008;8(1):79. DOI: 10.1186/1471-2288-8-79 PMID: 19036172

39. Skowronski DM, Chambers C, Sabaiduc S, Janjua NZ, Li $G$, Petric $M$, et al. Pre- and postpandemic estimates of 2009 pandemic influenza $A\left(\mathrm{H}_{1} \mathrm{~N}_{1}\right)$ seroprotection to inform surveillance-based incidence, by age, during the 2013-2014 epidemic in Canada. J Infect Dis. 2015;211(1):109-14. DOI: 10.1093/infdis/jiu366 PMID: 24973459

40. Foppa IM, Ferdinands JM, Chaves SS, Haber MJ, Reynolds SB, Flannery B, et al. The case test-negative design for studies of the effectiveness of influenza vaccine in inpatient settings. Int J Epidemiol. 2016;dyw022. DOI: 10.1093/ije/dyw022 PMID: 26979985

41. Castilla J, Martínez-Artola V, Salcedo E, Martínez-Baz I, Cenoz MG, Guevara M, et al. Vaccine effectiveness in preventing influenza hospitalizations in Navarre, Spain, 2010-2011: cohort and case-control study. Vaccine. 2012;30(2):195-200. DOI: 10.1016/j.vaccine.2011.11.024 PMID: 22100636

42. Skowronski DM, Chambers C, Sabaiduc S, De Serres G, Winter A-L, Dickinson JA, et al. A Perfect Storm: Impact of Genomic Variation and Serial Vaccination on Low Influenza Vaccine Effectiveness During the 2014-2015 Season. Clin Infect Dis. 2016;63(1):21-32. DOI: 10.1093/cid/ciw176 PMID: 27025838

43. Smith DJ, Forrest S, Ackley DH, Perelson AS. Variable efficacy of repeated annual influenza vaccination.Proc Natl Acad Sci USA. 1999;96(24):14001-6. DOI: 10.1073/pnas.96.24.14001 PMID: 10570188

44. McLean HQ, Thompson MG, Sundaram ME, Meece JK, McClure $\mathrm{DL}$, Friedrich TC, et al. Impact of repeated vaccination on vaccine effectiveness against influenza $A\left(\mathrm{H}_{3} \mathrm{~N}_{2}\right)$ and $B$ during 8 seasons. Clin Infect Dis. 2014;59(10):1375-85. DOI: 10.1093/cid/ ciu680 PMID: 25270645

\section{License and copyright}

This is an open-access article distributed under the terms of the Creative Commons Attribution (CC BY 4.0) Licence. You may share and adapt the material, but must give appropriate credit to the source, provide a link to the licence, and indicate if changes were made.

This article is copyright of the authors, 2017. 